nities, for example, may be appealing to someone with social anxiety issues.

"The research area of Internet addiction is relatively new and research is just beginning to understand the problem better," Daria Kuss, a senior lecturer in psychology at Nottingham Trent University in the United Kingdom, said in an email.

Relevant research and psychotherapists working in this area do indicate, however, that "comorbidity" of Internet addiction and other mental disorders tends to be common, noted Kuss, the lead author of a recent systematic review on Internet addiction and problematic Internet use in the World Journal of Psychiatry. But the issue of whether the Internet itself is the primary problem, or just a proxy for other issues, remains up for debate.
"This question is a tricky one," said Kuss, "and preliminary evidence would suggest that Internet addiction can be viewed both as a primary disorder (i.e., it is the individual's main concern) as well as a secondary disorder (it appears secondary to say depression or anxiety)." Roger Collier, CMAJ

CMAJ 2016. DOI:10.1503/cmaj.109-5336

\title{
Doctors seek legal advice over assisted dying
}

$\mathrm{T}$ he Canadian Medical Protective Association (CMPA) opened some 152 legal files for physicians related to medical assistance in dying (MAID) between June 17 (when the federal law took effect) and Aug. 4, 2016.

Since August 2015, the 95 000-member not-for-profit medical mutual defence organization, has opened a total of about 272 files on the issue, Public Affairs Supervisor Joel Baglole stated in an email.

"The spike in call volumes we did receive following June 17 was expected. The rate of new calls seems to be declining somewhat in recent weeks," Baglole said.

The CMPA reaffirmed its commitment to help physicians struggling with new assisted-dying legislation at its recent annual meeting.

Quebec's law on assisted dying was upheld by the courts in 2015, and a federal law received Royal assent in June after passionate debate about whether it conformed to a Supreme Court decision affirming Canadians' right to assisted death.

The CMPA passed resolutions at its 2015 annual meeting calling on the association to help doctors "in matters involving the exercise of their freedoms of conscience, religion, and professional judgement," and expressing concern about "mandatory obligations that interfere with those freedoms."

Outgoing president Dr. Edward Crosby told this year's meeting in Vancouver that "MAID has been a seminal development in our country's laws and in the role our members will be asked to play in a patient's end-of-

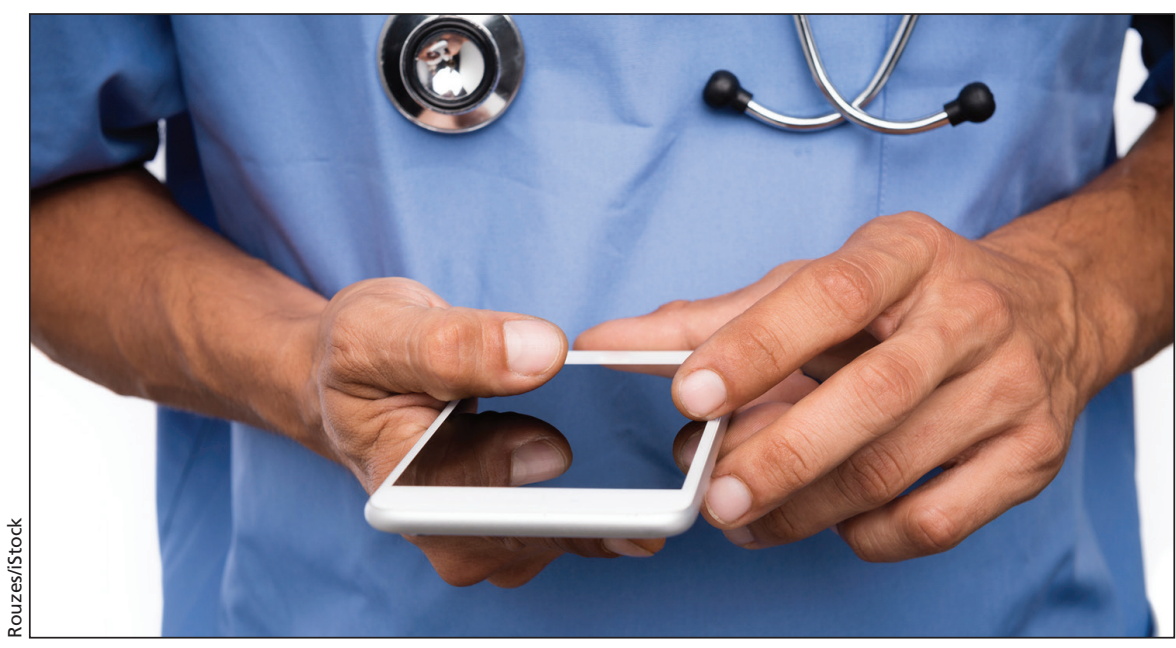

More than $\mathbf{2 0 0}$ doctors have sought legal advice about medically assisted dying.

life care. We have taken what was asked of us seriously."

The association was an active participant as the federal law was drafted and practice standards developed, "always with the objective to provide clarity and consistency across the country, ensure protection for physicians acting in good faith and to protect the interests of our members," said Crosby.

The CMPA was pleased some of its recommendations found their way into new law, he said. They include a statement in the preamble calling for a consistent approach to assisted dying across Canada, clearly spelled out eligibility criteria and safeguards, clear requirements related to the age of consent and need for a "good faith" provision protecting medical practitioners from criminal liability if they acted on an assisted-dying request in an honest but mistaken belief.

"We have seen a reduction in the number of calls from Québec, which can be explained by the fact that institutions in that province have now put in place MAID teams and committees to assist physicians in dealing with a patient's request for MAID," Baglole told CMAJ.

The CMPA and its provincial legal counsel are helping members to ensure they're familiar with and comply with the law's framework, said Baglole. They are also helping doctors understand the eligibility criteria, "especially the requirement that the patient suffers from a grievous and irremediable medical condition."

As well, CMPA lawyers are helping doctors who don't want to be involved with assisted dying and with practical issues such as family opposition to a patient's request or where a hospital does not have a MAID policy, he said.

"It is our intention to assist physicians by identifying your potential medical-legal risks based upon the individual scenario facing you at the time," Crosby said. - Steve Mertl, Vancouver, BC

CMAJ 2016. DOI:10.1503/cmaj.109-5324 